\title{
The association between linoleic acid levels in colostrum and child cognition at 2 and 3 y in the EDEN cohort
}

\author{
Jonathan Y. Bernard ${ }^{1,2}$, Martine Armand ${ }^{3}$, Cyrielle Garcia ${ }^{3}$, Anne Forhan ${ }^{1,2}$, Maria De Agostini ${ }^{1,2}$, Marie-Aline Charles ${ }^{1,2,4}$ and
} Barbara Heude ${ }^{1,2}$; the EDEN Mother-Child Cohort Study Group

BACKGROUND: Breastfeeding has been associated with improved cognitive development. This may be explained by polyunsaturated fatty acid (PUFA) content of breast milk, especially long-chain (LC) PUFA that are needed for postnatal brain growth.

METHODS: Using data from the French EDEN cohort, we aimed to study whether the PUFA content of colostrum may explain observed associations between breastfeeding duration and cognitive scores at 2 and 3 y. A total of 709 breastfed children with available data on PUFA composition of milk were assessed using parent-reported questionnaires for motor and language at $2 \mathrm{y}$ of age, or global cognition at $3 \mathrm{y}$. Multiple linear regressions were used to examine associations between PUFA levels and child cognitive scores, after controlling for many confounders.

RESULTS: We found no association between LCPUFA levels in colostrum and child development. However, levels of linoleic acid (LA) were negatively associated with motor and cognitive scores, independently of breastfeeding duration. Children breastfed with the highest levels of LA tended to score closer to the never breastfed children than children breastfed with the lowest levels of LA.

CONCLUSION: Our findings suggest that too high levels of $L A$ in colostrum are associated with poorer child development at 2 and $3 y$.

O bservational studies have shown that breastfed children have higher scores of cognitive development than formula-fed children $(1,2)$. In the EDEN mother-child cohort study, we recently reported a positive and linear association between breastfeeding duration and child development at 2 and $3 \mathrm{y}$, suggesting a dose-response relationship (3), a result also confirmed at different ages in other birth cohorts $(4,5)$. However, some authors have challenged the causality of the observed association, since some observational studies did not find significant association after controlling for confounders such as parental education and maternal IQ $(6,7)$. One biological hypothesis for a potential effect of breastfeeding on cognitive development is the breast milk content in $\omega 6$ (n-6) and $\omega 3$ (n-3) polyunsaturated fatty acids (PUFA), especially the longchain PUFA (LCPUFA) such as arachidonic acid (AA, 20:4 n-6) and docosahexaenoic acid (DHA, 22:6 n-3). AA and DHA are needed for fetus and infant brain development (8). The n-6 and n-3 LCPUFA are either provided directly by feeding, or biosynthesized from their respective precursors, the linoleic acid (LA, 18:2 n-6) and the $\alpha$-linolenic acid (ALA, 18:3 n-3).

Randomized controlled trials that investigated LCPUFA supplementation in both term and preterm infants remain inconclusive, since some randomized controlled trials showed a positive effect of LCPUFA-enriched formulas on child cognition and others found no difference with control group $(9,10)$. The potential effects of ALA- or LA-enriched formulas on cognition are poorly documented and not demonstrated (11). To date, few data from observational studies are available and their results are inconsistent. The largest one used the data from the Spanish INMA mother-child cohort and included 504 infants aged $14 \mathrm{mo}$. The authors showed that mental development score, as measured with the Bayley's Scales on Infant Development, was five points higher among infants exposed to both the higher intensity of breastfeeding and colostrum with low n-6/n-3 ratio, than among infants less exposed to breastfeeding, as well as those exposed to colostrum with higher $\mathrm{n}-6 / \mathrm{n}-3$ ratio (12). The follow-up of the participants to $4 \mathrm{y}$ of age, did not confirm this finding: the colostrum content in n-3 PUFA was not associated with cognitive development, as measured with the McCarthy Scales of Children's Abilities (13). At the same time, a smaller study of 51 preterm infants of 6 mo of age reported a negative association between the levels of the n- 6 precursor LA in transitional breast milk and both mental and emotional scales of the Bayley's Scales of Infant Development (14). Using data from our large mother-child cohort study, we aimed to explore the associations of PUFA and LCPUFA levels in colostrum with cognition in early childhood.

\section{RESULTS}

Compared to the breastfeeding mothers who gave colostrum sample, those who did not give sample of colostrum were most likely to have been recruited in Poitiers ( 63 vs. $33 \%, P<0.0001$ ), to have a higher BMI (mean difference: $0.8 \mathrm{~kg} / \mathrm{m}^{2}, P=0.004$ ), 
a lower education (mean difference: $0.5 \mathrm{y}, P=0.001$ ) and to breastfeed for a shorter duration (mean difference: $0.7 \mathrm{mo}, P$ $=0.0001$ ) (results not shown). They did not differ according to age, smoking status, and alcohol consumption during pregnancy, nor according to sex and gestational age of their offspring. Characteristics and comparisons of the mother-child pairs with colostrum analysis that were followed or not at the ages of 2 and $3 \mathrm{y}$ are presented in Table 1. PUFA levels and ratios in colostrum of mother-child pairs followed and not followed at 2 and 3 y are described in Table 2. Briefly, average levels of LA, AA, and DHA in colostrum of mothers of children still followed at 2 and 3 y were respectively 9.8 $\pm 1.8 \%$ (Mean $\pm \mathrm{SD}), 0.86 \pm 0.15 \%$, and $0.63 \pm 0.19 \%$, and the total $n-6 / n-3$ PUFA ratio was on average $6.2 \pm 1.5$. Levels of PUFA did not differ in followed and lost to follow-up populations, except the total n-6 LCPUFA that was slightly lower in followed participants $(P=0.02)$. Levels of PUFA did not differ according to child sex. Mean child ages and scores at the cognitive assessments are shown in Table 3.

In multivariable linear models with PUFA levels used as continuous variables, LA levels were negatively and significantly associated with Motor-2 $(\beta=-0.10,95 \%$ confident interval $(\mathrm{CI})=-0.20 ;-0.01))$ and ASQ-3 $(\beta=-1.9, \mathrm{CI}=-3.1,-0.8)$ (Table 4). The association between LA levels and CDI-2 was also negative but nonsignificant. These associations were quite similar when considering total n-6 PUFA levels. The departure from linearity was rejected for the latter associations with ASQ-3, but not for those with Motor-2 (results not shown). No associations or consistent trends were observed with n-3 PUFA levels or with n-6/n-3 ratios.

The Table 5 shows the results of the comparison of motor and cognitive scores according to three groups: never breastfed children, breastfed children exposed to the lowest LA levels in colostrum (5.4-9.7\%), and breastfed children exposed to the highest LA levels (9.7-15.9\%) in colostrum. The children from the "Lowest LA levels" group scored significantly higher in Motor-2 and in ASQ-3 than those from both the groups "Never breastfed" and "Highest LA levels". The difference between the groups "Never breastfed" and "Highest LA levels" tended to be significant with ASQ-3 only, in favor of "Highest LA levels". For CDI-2, the global difference between the three groups tended to be significant $(P=0.09)$ and was mainly due to the difference between the groups "Lowest LA levels" and "Highest LA levels".

The previously observed associations between breastfeeding duration and motor and cognitive scores did not differ when the variable of each PUFA was added to the models. Finally, we found no consistent interaction between the PUFA or LC-PUFA levels in colostrum and breastfeeding duration (data not shown).

\section{DISCUSSION}

In the EDEN mother-child cohort study, negative associations were found between LA levels in colostrum and child motor and cognitive scores at 2 and 3 y of age. By contrast, no association was shown between LCPUFA levels (AA or DHA) in
Table 1. Characteristics of the exclusively breastfed children followed and not followed at 2 and $3 y$ in the EDEN cohort

\begin{tabular}{|c|c|c|c|}
\hline Characteristics of participants & $\begin{array}{l}\text { Followed } \\
(n=709)^{\text {a }}\end{array}$ & $\begin{array}{l}\text { Not followed } \\
\quad(n=159)^{a}\end{array}$ & $P^{b}$ \\
\hline \multicolumn{4}{|l|}{ Maternal characteristics } \\
\hline $\begin{array}{l}\text { Recruitment centre, \% (n) } \\
\text { from Poitiers }\end{array}$ & $34.7(246)$ & $34.6(55)$ & 0.98 \\
\hline Age at conception, $y$ & $29.3 \pm 4.6$ & $28.2 \pm 4.9$ & 0.01 \\
\hline Prepregnancy BMI, kg/m² & $22.6 \pm 4.1$ & $23.5 \pm 5.1$ & 0.04 \\
\hline $\begin{array}{l}\text { Smoking during pregnancy, } \\
\%(n)\end{array}$ & $21.6(153)$ & $33.3(53)$ & 0.002 \\
\hline Alcohol consumption, $\%(n)$ & & & 0.66 \\
\hline Never & $58.7(416)$ & $60.8(96)$ & \\
\hline$<10 \mathrm{~g} / \mathrm{wk}$ & $35.0(248)$ & $31.7(50)$ & \\
\hline$\geq 10 \mathrm{~g} / \mathrm{wk}$ & $6.4(45)$ & $7.6(12)$ & \\
\hline \multicolumn{4}{|l|}{ Child characteristics } \\
\hline Sex, $\%(n)$ of boys & $50.1(355)$ & $53.5(85)$ & 0.44 \\
\hline Gestational age, wk & $39.4 \pm 1.3$ & $39.3 \pm 1.4$ & 0.40 \\
\hline $\begin{array}{l}\text { Exclusive breastfeeding } \\
\text { duration, mo }\end{array}$ & $3.0 \pm 3.0$ & $2.5 \pm 2.1$ & 0.02 \\
\hline \multicolumn{4}{|l|}{$\begin{array}{l}\text { Family and social environment } \\
\text { characteristics }\end{array}$} \\
\hline Firstborn, \% (n) & $47.0(333)$ & $35.2(56)$ & 0.007 \\
\hline Parental education, $y$ & $14.0 \pm 2.3$ & $12.8 \pm 2.3$ & 0.0001 \\
\hline Household income class, \% ( $n$ ) & & & 0.0001 \\
\hline$\leq 800 €$ & $0.7(5)$ & $8.2(13)$ & \\
\hline $801-1,500 €$ & $5.5(40)$ & $13.9(22)$ & \\
\hline $1,501-2,300 €$ & $17.3(125)$ & $30.4(48)$ & \\
\hline $2,301-3,000 €$ & $31.9(230)$ & $23.4(37)$ & \\
\hline $3,001-3,800 €$ & $23.4(169)$ & $12(19)$ & \\
\hline $3,801-4,500 €$ & $12.9(93)$ & $7.6(12)$ & \\
\hline$>4,500 €$ & $6.5(47)$ & $4.4(7)$ & \\
\hline
\end{tabular}

Frequency of mother-child activities, \% (n)

$\begin{array}{ll}<2 \text { time/wk } & 20.1(145) \\ \text { 3-6 times/wk } & 45.6(329) \\ \geq 7 \text { times/wk } & 32.5(235)\end{array}$

Main daytime caregiver at $2 \mathrm{y}, \%(n)$

Mother/family $\quad 36.4(258)$

Nursery/babysitter $\quad 63.6(451)$

Preschooled at $3 \mathrm{y}, \%(n) \quad 64.4(394)^{c}$

${ }^{a}$ Data are presented in mean \pm SD or percentage (number). ${ }^{b}$ Data are tested using $t$-test or $\chi^{2}$ test. 'Among children followed at 3 y of age $(n=612)$.

colostrum and child motor skills and cognition. These associations did not differ according to breastfeeding duration and did not modify the associations between breastfeeding duration and cognition.

The results of the present study are in agreement with the few previous observational studies that investigated LCPUFA 
Table 2. Descriptive PUFA levels in colostrum from breastfeeding mothers of followed and not followed children at 2 and $3 y$ in the EDEN cohort

\begin{tabular}{|c|c|c|c|}
\hline \multirow[b]{2}{*}{ Fatty acids $^{\mathrm{a}}$} & Followed $(n=709)$ & Not followed ( $n=159)$ & \multirow[b]{2}{*}{$P^{\mathrm{b}}$} \\
\hline & Mean $\pm S D(Q 1-Q 3)$ & Mean \pm SD (Q1-Q3) & \\
\hline \multicolumn{4}{|l|}{ n-6 PUFA } \\
\hline $18: 2 n-6(L A)$ & $9.8 \pm 1.8(8.6-10.8)$ & $10 \pm 2.1(8.5-10.9)$ & 0.46 \\
\hline $20: 4 n-6(A A)$ & $0.86 \pm 0.15(0.75-0.96)$ & $0.9 \pm 0.2(0.7-1.0)$ & 0.09 \\
\hline $\begin{array}{l}\text { Total n-6 } \\
\text { PUFA }\end{array}$ & $12.2 \pm 1.8(10.9-13.2)$ & $12.4 \pm 2.2(10.8-13.4)$ & 0.22 \\
\hline $\begin{array}{l}\text { Total } n-6 \\
\text { LCPUFA }\end{array}$ & $2.1 \pm 0.4(1.8-2.3)$ & $2.2 \pm 0.5(1.9-2.5)$ & 0.02 \\
\hline \multicolumn{4}{|l|}{ n-3 PUFA } \\
\hline $\begin{array}{l}18: 3 n-3 \\
\text { (ALA) }\end{array}$ & $0.65 \pm 0.22(0.49-0.78)$ & $0.6 \pm 0.2(0.5-0.7)$ & 0.33 \\
\hline $\begin{array}{l}20: 5 n-3 \\
\text { (EPA) }\end{array}$ & $0.06 \pm 0.03(0.04-0.07)$ & $0.1 \pm 0.0(0.0-0.1)$ & 0.57 \\
\hline $\begin{array}{l}22: 6 n-3 \\
(D H A)\end{array}$ & $0.63 \pm 0.19(0.50-0.74)$ & $0.6 \pm 0.2(0.5-0.8)$ & 0.60 \\
\hline $\begin{array}{l}\text { Total n-3 } \\
\text { PUFA }\end{array}$ & $2.04 \pm 0.41(1.76-2.28)$ & $2.1 \pm 0.4(1.7-2.3)$ & 0.72 \\
\hline $\begin{array}{l}\text { Total n-3 } \\
\text { LCPUFA }\end{array}$ & $1.22 \pm 0.31(0.99-1.39)$ & $1.2 \pm 0.3(1.0-1.4)$ & 0.33 \\
\hline \multicolumn{4}{|l|}{$\begin{array}{l}\mathrm{n}-6 / \mathrm{n}-3 \text { PUFA } \\
\text { ratios }\end{array}$} \\
\hline LA/ALA & $16.5 \pm 5.4(12.5-19.9)$ & $17.2 \pm 5.9(12.7-20.6)$ & 0.14 \\
\hline $\mathrm{AA} / \mathrm{DHA}$ & $1.4 \pm 0.4(1.2-1.7)$ & $1.5 \pm 0.4(1.2-1.7)$ & 0.33 \\
\hline $\begin{array}{l}\text { Total n-6/n-3 } \\
\text { PUFA }\end{array}$ & $6.2 \pm 1.5(5.1-7.0)$ & $6.3 \pm 1.7(5.1-7.3)$ & 0.42 \\
\hline $\begin{array}{l}\text { Total n-6/n-3 } \\
\text { LCPUFA }\end{array}$ & $1.8 \pm 0.4(1.5-2.1)$ & $1.8 \pm 0.4(1.5-2.1)$ & 0.17 \\
\hline
\end{tabular}

avalues are expressed as \% of total fatty acids. 'Data are tested using t-tests. AA, arachidonic acid; ALA, $\alpha$-linolenic acid; DHA, docosahexaenoic acid; EPA, eicosapentaenoic acid; LA, linoleic acid; PUFA, polyunsaturated fatty acid.

Table 3. Characteristics of cognitive scores and ages at assessment of children in the EDEN cohort

\begin{tabular}{|c|c|c|c|}
\hline & $n$ & Score ${ }^{a}$, point & $\begin{array}{c}\text { Age at } \\
\text { assessment }{ }^{\mathrm{a}}, \mathrm{mo}\end{array}$ \\
\hline \multicolumn{4}{|c|}{ Neurodevelopmental assessment } \\
\hline Motor-2 & 652 & $16.4 \pm 2.2(7-22)$ & $24.3 \pm 0.6(23.1-27.4)$ \\
\hline CDI-2 & 657 & $62.8 \pm 29.1(1-100)$ & $24.3 \pm 0.6(23.1-26.9)$ \\
\hline ASQ-3 & 568 & $274.7 \pm 24.9(90-300)$ & $37.8 \pm 0.7(35.3-39.9)$ \\
\hline
\end{tabular}

levels in colostrum, transitional or mature breast milk, in relation with later child cognition, and that found no strong evidence for a beneficial role of LCPUFA, in order to explain the relationship between breastfeeding and cognition (12-16). Most of the literature on this topic comes from randomized controlled trials. A systematic review of randomized controlled trials concluded to no clear benefit of LCPUFA supplementation on cognitive development in children born at term (9). We found negative associations between the levels
Table 4. Adjusted associations of continuous PUFA levels in colostrum of breastfeeding mothers with child motor and cognitive scores at 2 and $3 y$ in the EDEN cohort

\begin{tabular}{|c|c|c|c|}
\hline & $\begin{array}{c}{\text { Motor- }-2^{b}}_{n=652}\end{array}$ & $\begin{array}{l}\text { CDI- } 2^{b} \\
n=657\end{array}$ & $\begin{array}{l}\text { ASQ }^{\text {b }}{ }^{\circ} \\
n=568\end{array}$ \\
\hline Fatty acids ${ }^{a}$ & $\beta(95 \% \mathrm{Cl})$ & $\beta(95 \% \mathrm{Cl})$ & $\beta(95 \% \mathrm{Cl})$ \\
\hline \multicolumn{4}{|l|}{ n-6 PUFA } \\
\hline $18: 2 n-6(L A)$ & $-0.1(-0.2,0.0)^{*}$ & $-0.6(-1.9,0.6)$ & $-1.9(-3.1,-0.8)^{*}$ \\
\hline $20: 4 n-6(A A)$ & $-0.8(-1.9,0.4)$ & $0.2(-14.6,15.1)$ & $-2.3(-16.5,11.9)$ \\
\hline Total n-6 PUFA & $-0.1(-0.2,0.0)^{*}$ & $-0.6(-1.8,0.6)$ & $-2(-3.1,-0.9)^{* *}$ \\
\hline $\begin{array}{l}\text { Total n-6 } \\
\text { LCPUFA }\end{array}$ & $-0.3(-0.7,0.2)$ & $0.4(-5.5,6.2)$ & $-2.8(-8.4,2.8)$ \\
\hline \multicolumn{4}{|l|}{ n-3 PUFA } \\
\hline $18: 3 n-3$ (ALA) & $0.1(-0.7,1.0)$ & $0.7(-9.7,11.1)$ & $-3.9(-13.7,5.9)$ \\
\hline $20: 5 n-3$ (EPA) & $-2.0(-7.7,3.6)$ & $15.7(-56.2,87.6)$ & $-34.9(-103.5,33.7$ \\
\hline $22: 6 n-3(\mathrm{DHA})$ & $-0.7(-1.7,0.3)$ & $5.5(-6.8,17.8)$ & $-1.2(-12.8,10.5)$ \\
\hline Total n-3 PUFA & $-0.2(-0.6,0.3)$ & $2.4(-3.1,7.9)$ & $-0.6(-5.8,4.7)$ \\
\hline Total n-3 & $-0.4(-1.0,0.2)$ & $3.4(-4.1,10.9)$ & $0.7(-6.3,7.7)$ \\
\hline
\end{tabular}

$\mathrm{n}-6 / \mathrm{n}-3$ PUFA ratios

$$
\begin{array}{lrrc}
\text { LA/ALA } & 0.0(-0.1,0.0) & -0.1(-0.6,0.3) & -0.2(-0.6,0.2) \\
\text { AA/DHA } & 0.3(-0.2,0.8) & -2.2(-8.4,4.1) & 1.6(-4.6,7.7) \\
\text { Total n-6/n-3 } & -0.1(-0.2,0.1) & -1.0(-2.5,0.5) & -\mathbf{1 . 5}(-\mathbf{2 . 9},-\mathbf{0 . 1})^{*} \\
\text { PUFA } & & & \\
\text { Total n-6/n-3 } & 0.1(-0.4,0.6) & -2.9(-9.0,3.1) & -3.3(-9.2,2.6)
\end{array}
$$
LCPUFA

Values in bold are significant $<0.05$. avalues are expressed as $\%$ of total fatty acids. ${ }^{b}$ Data presented are regression coefficients ( $95 \%$ confidence interval). The motor and cognitive scores have to be interpreted as the higher, the better. Models were adjusted for centre, child's sex, gestational age, child age, maternal age, maternal prepregnancy $\mathrm{BMI}$, tobacco and alcohol consumption during pregnancy, parental education,

household income, sibling, caregivers at $2 y$, school attendance at $3 y$, day of colostrum collection, exclusive breastfeeding duration. ${ }^{*}<0.05 ;{ }^{* *}<0.01 ; * * *<0.001$.

AA, arachidonic acid; ALA, $\alpha$-linolenic acid; DHA, docosahexaenoic acid; EPA, eicosapentaenoic acid; LA, linoleic acid; PUFA, polyunsaturated fatty acid.

of the n-6 precursor LA and two measures of development, Motor-2 and ASQ-3, together with a nonsignificant negative relationship with the CDI-2. Such association was previously highlighted among 51 preterm infants of 6 mo of age (14). In other studies, authors reported negative associations between cognition and PUFA ratios, especially LA/ALA, AA/ DHA, and total n-6/n-3 (12,14,15). In our study, we observed a negative and significant association between total $n-6 / n-3$ PUFA ratio and the ASQ-3 score, but this was not observed with Motor-2 and CDI-2. Finally, we did not find interactions between PUFA or LCPUFA levels and breastfeeding duration, contrary to Guxens and collaborators, who highlighted that infants intensely breastfed with colostrum with lower n-6/n-3 ratio scored higher at 14 mo, than both infants breastfed for a shorter time and infants exposed to colostrum with a higher n-6/n-3 ratio (12). However, this interaction was not confirmed by the authors when considering longer follow-up at 4 y (13). Compared to the INMA cohort, the EDEN cohort was characterized by a shorter exclusive breastfeeding duration 
Table 5. Adjusted means of child motor and cognitive scores at 2 and $3 y$ among children from the EDEN cohort who were either never breastfed, breastfed with colostrum containing the highest, or the lowest LA levels

\begin{tabular}{lccc}
\hline & Motor-2 & CDI-2 & ASQ-3 \\
\cline { 2 - 4 } & Mean \pm SEM & Mean \pm SEM & Mean \pm SEM \\
\hline Global $P$ & 0.003 & 0.09 & 0.0002 \\
Never breastfed $^{\mathrm{a}}$ & $15.9 \pm 0.2^{\mathrm{b}}$ & $56.4 \pm 2.0$ & $261.5 \pm 2.2^{\mathrm{d}}$ \\
Highest LA levels $^{\mathrm{a}}$ & $16.1 \pm 0.2^{\mathrm{c}}$ & $55.3 \pm 1.9$ & $266.4 \pm 2.0^{\mathrm{e}}$ \\
Lowest LA levels $^{\mathrm{a}}$ & $16.5 \pm 0.2^{\mathrm{b}, \mathrm{c}}$ & $60.0 \pm 1.9$ & $272.2 \pm 2.0^{\mathrm{d}, \mathrm{e}}$ \\
\hline
\end{tabular}

values are adjusted mean \pm SEM. Lowest LA levels are comprised between 5.4 and 9.7\% of total fatty acids; highest LA levels are comprised between 9.7 and $15.9 \%$ of total fatty acids. Models were adjusted for centre, child's sex, gestational age, child age, maternal age, maternal prepregnancy BMI, tobacco and alcohol consumption during pregnancy, parental education, household income, sibling, caregivers at $2 y$, schooled at $3 y$, day of colostrum collection, exclusive breastfeeding duration. Letters ${ }^{b, c, d}$, and ${ }^{e}$ indicate the groups that are significantly different each other.

$L A$, linoleic acid.

( 3 mo vs. around $4 \mathrm{mo}$ ) and a substantially lower total $\mathrm{n}-6 /$ n-3 PUFA ratio in colostrum (6.2 vs. 10.6). These differences could explain the discordance between their results and ours. Moreover, the average short duration of breastfeeding in our cohort could have led to a lack of power in the interaction tests.

The main strength of our study is the large sample size, since this is the first one to use more than 700 samples of colostrum with PUFA levels analysis. The previous studies have analyzed half as many breast milk samples as our study, since the two publications from the INMA cohort have used the method of multiple imputations to bring the sample size to 500. However, our measure of child exposure to PUFA has some limitations. First, we did not consider the individual exposure to PUFA and LCPUFA of never breastfed children through infant formulas. In our cohort, the composition of the formulas given to the infants revealed that the great majority of them were not enriched in LCPUFA, and all formulas had LA levels higher than $10.8 \%$ of total fatty acids, with an average level of $15.5 \%$ of total fatty acids. The second limitation is that we were not able to estimate PUFA levels throughout breastfeeding duration, since mature breast milk was not collected in the EDEN study. Both randomized controlled trials and observational studies support that PUFA levels vary during the course of lactation, depending on maternal diet and fat storage, as well as genetic determinants of de novo biosynthesis (17-20). In our analysis, we used PUFA levels in colostrum as a proxy of postnatal PUFA exposure, considering that women with higher levels of a given PUFA in colostrum are likely to remain with higher levels in mature milk compared to their counterparts, as long as they keep on the same type of diet. The observed associations with colostrum, considered as an early postnatal exposure, could also reflect a prenatal exposure to PUFA, through maternal diet. We previously highlighted a negative association between maternal LA intake during the last trimester of pregnancy and child motor skills and cognition at 2 and $3 y$ in our cohort (21). However, this relation was observed among never breastfed children only. Taken together, these results suggest that a too high exposure to LA during both prenatal and early postnatal period is associated with a poorer motor and cognitive development in childhood. The main dietary sources of LA among EDEN pregnant women were sauces and vegetable oils, snack food, ready-prepared meals and bread, i.e., food groups linked to the Western diet and lifestyle. In complementary analyses, we found only moderate correlations between maternal PUFA intake during the last trimester of pregnancy and PUFA levels in colostrum. The correlation between DHA intake and DHA levels was the highest that we have observed $(0.33 ; P<0.0001)$. We found a low but significant correlation of $0.16(P<0.0001)$ between maternal LA intake and LA levels in colostrum. However in sensitivity analyses, the adjustment for maternal LA intake did not change our present results. Finally, motor and cognitive scores of children breastfed with colostrum containing the highest LA levels appeared to be closer to those of never breastfed children than those breastfed with colostrum containing the lowest LA levels. Though clinically nonsignificant, this effect size cannot be neglected since it corresponds in our study to half of the difference in scores observed between girls and boys.

The prospective design of the EDEN study from pregnancy to childhood was a strength to evaluate accurately breastfeeding practice and child cognition, as well as a wide range of covariates to adjust for. Even if crude associations were slightly affected by adjustment, we cannot rule out the risk of confounding in such observational study. Even if the cohort studies are exposed to selective attrition, the quality of the follow-up of the EDEN study is suitable and comparable to other mother-child cohorts. Motor and cognitive development at 2 and $3 \mathrm{y}$ was assessed using parent-reported questionnaires and not by psychologists. However, these questionnaires are tools of choice for large epidemiological studies and their validity against standardized tests have been confirmed $(22,23)$. Finally, we also assume not having adjusted our analyses for multiple comparisons, as recommended by Rothman for epidemiological research (24). Actually, our study is built upon existing empirical studies and we have been careful to not overinterpret inconsistent results.

The negative impact of the highest LA levels, i.e., $<9.7 \%$ of total fatty acids, can be explained through different pathways. First, the synthesis of n- 6 and n-3 LCPUFA compete for the same enzymes, especially $\Delta-5$ and $\Delta-6$ desaturases, which are encoded by FADS1 and FADS2 genes, respectively (25). It has been suggested that a high n-6 PUFA intake, especially LA, may decrease the biosynthesis of n-3 LCPUFA (26), diminishing the endogenous DHA supply necessary for organs development. A second hypothesis based on an animal model is that the excess of dietary and then circulating LA could decrease the uptake of DHA from circulation by the brain, and thus accretion/sequestration rate of DHA into the brain $(27,28)$. Thirdly, n-6 PUFA, and mainly AA, are known to be the precursors of proinflammatory eicosanoids (29). A chronic inflammation caused by an excess in n-6 PUFA intake was associated with a higher risk for Alzheimer disease (30). This chronic inflammatory process could also occur during early life through a too high dietary exposure to LA. The low to null relationship of 
DHA levels of our colostrum samples with child development could be related to the form of DHA in human milk; indeed, DHA is provided either by triglycerides or phospholipids (31). The phospholipid form was shown to be more effective in carrying DHA to the brain (32). In general, fatty acid composition of human milk is conducted on total lipids and do not inform on the levels of DHA specifically carried by phospholipids that is very variable among milk samples (31). Another explanation could be the relatively high levels of DHA in our colostrum samples (only 20 samples containing $0.20-0.35 \%$ DHA); one can imagine that a clearer relationship should be raised with milk samples showing a larger deficit in DHA. Although there is strong evidence for a DHA requirement for the developing brain in early life, our results do not support a limiting effect of the DHA content found in our colostrum samples.

In conclusion, using data from the French EDEN motherchild cohort study, we aimed to investigate whether there were associations of PUFA and LCPUFA in colostrum with child motor skills and cognition at 2 and $3 \mathrm{y}$ of age, as assessed with parent-reported questionnaires, and taking into account breastfeeding duration and many known confounders. We showed that, independently of breastfeeding duration, the highest LA levels in colostrum were associated with poorer motor and cognitive development at ages 2 and $3 \mathrm{y}$. This relationship needs to be further investigated later in childhood and in other birth cohorts. If the existence of such relationship is confirmed, recommendations for formula composition should be revised in order to reduce infant LA intake.

\section{METHODS}

\section{Design and Study Population}

The EDEN study is a French mother-child cohort that aims to investigate the role of pre- and postnatal determinants of child development and health. Recruitment started in 2003 in the university hospitals of Poitiers and Nancy and lasted 27 mo. All pregnant women presenting to their first antenatal visit before $24 \mathrm{wk}$ of amenorrhea were invited to participate in the cohort. Exclusion criteria were multiple pregnancies, known diabetes prior to pregnancy, illiteracy, and intention to move outside the region in the next $3 \mathrm{y}$. A total of 2002 women were enrolled. Details of the EDEN study protocol have been published elsewhere (33). Informed written consents concerning the parents were obtained at enrolment, and that for the child was obtained from the mother and, if available, the father, after the child birth. The study was approved by the ethics research committee (Comité Consultatif de protection des personnes dans la recherche biomédicale) of the Bicêtre Hospital, and by the Data Protection Authority (Commission Nationale de l'Informatique et des Libertés).

\section{Colostrum Sampling and Analysis of Fatty Acids Composition}

Among breastfeeding mothers who agreed to give colostrum sample, about $5 \mathrm{ml}$ were collected during the first week after delivery (Mean \pm SD: $3.9 \pm 1.1 \mathrm{~d}$ ). Samples were stored at $-80^{\circ} \mathrm{C}$ until biological analysis. A direct transmethylation was performed on $100 \mu \mathrm{l}$ of colostrum at $10{ }^{\circ} \mathrm{C}$ during $1 \mathrm{~h}$ following a previously described method (34). Fatty acid methyl esters were analyzed by fast gas chromatography with a Clarus 600 Gas Chromatograph equipped with the TotalChrom data system and a flame ionization detector (PerkinElmer Instruments LLC, Shelton, CT), using hydrogen as gas carrier and a fused silica capillary column (BPX 70 with $10 \mathrm{~m} \times 0.1 \mathrm{~mm}$ i.d. and $0.2 \mu \mathrm{m}$ film thickness, SGE Analytical Science, Milton Keynes, UK). Oven temperature rise of $20^{\circ} \mathrm{C} / \mathrm{min}$ was applied from 60 to $200^{\circ} \mathrm{C}$, then $7^{\circ} \mathrm{C} /$ min to $225^{\circ} \mathrm{C}$ with a $1 \mathrm{~min}$ hold and finally $160^{\circ} \mathrm{C} / \mathrm{min}$ to $250^{\circ} \mathrm{C}$ with a 1 min hold. Identification was based on the retention time with respect to fatty acid methyl ester standards (PUFA 2, Sigma-Supelco, Saint-Quentin-Fallavier, France). Fatty acids were expressed as proportion of total milk fat (wt\% of total fatty acids). Some measurements were done in duplicate to verify the reproducibility of the procedure. Internal standard (tridecanoic acid, Sigma-Fluka, SaintQuentin-Fallavier, France) was added to quantify total lipid. Twelve well represented PUFA (i.e., levels $>0.05 \%$, six $n-6$ and six $n-3$ ) were identified in the colostrum: linoleic acid (LA, 18:2 n-6), $\gamma$-linolenic acid (18:3n-6), dihomo- $\gamma$-linolenic acid (20:3 n-6), arachidonic acid (AA, 20:4 n-6), adrenic acid (22:4 n-6), n-6 docosapentaenoic or osbond acid (22:5n-6), alpha-linolenic acid (ALA, 18:3 n-3), stearidonic acid (18:4n-3), eicosatetraenoic acid (20:4 n-3), eicosapentaenoic acid (EPA, 20:5 n-3), n-3 docosapentaenoic or clupanodonic acid $(22: 5 n-3)$, and docosahexaenoic acid (DHA, 22:6n-3). Among these PUFA, we chose to focus on five of interest, because of their essential roles in infancy, and their relative high levels in human breast milk, as highlighted in the literature (8): the two precursors LA and ALA, and their derivatives AA, EPA, and DHA. We calculated the total n-6 PUFA, the total n-6 LCPUFA (with 20 carbons or more), the total $n-3$ PUFA, the total n-3 LCPUFA (with 20 carbons or more). Because of the competition between $n-6$ and $n-3$ series for the same enzymes, we also considered some $n-6 / n-3$ ratios, i.e., LA/ALA, AA/DHA, total n-6/n-3 PUFA, and total n-6/n-3 LCPUFA.

\section{Cognitive Assessments}

In the 2-y questionnaire, the child motor development (Motor2) was evaluated using motor items of the French Psychomotor Developmental Scale for Early Childhood of Brunet-Lézine (35). We summed the items to obtain a score between 0 and 22 points. The child language ability was evaluated with the short French version of the MacArthur Communicative Development Inventory (CDI2) $(36,37)$. Parents reported from a list of 100 words, those that the child was able to pronounce spontaneously. The CDI-2 score ranged between 0 and 100. Cognition was investigated at $3 \mathrm{y}$ of age, with the second French edition of the Ages and Stages Questionnaire (ASQ-3) (38), which is a parent-reported assessment including five domains of development (communication, gross motor, fine motor, problem solving and personal-social). For each of the 30 questions, a child scored 10 points when parents reported the child had this ability, 5 points when the behavior was occasionally observed by parents and 0 points otherwise. The total ASQ-3 score ranged between 0 and 300 points. The three scores have to be interpreted as the higher, the better.

\section{Covariates}

During a visit between 24 and 28 wk of gestation, research midwives measured maternal height and mothers declared weight before pregnancy. Prepregnancy body mass index (BMI) was calculated (in kg/ $\mathrm{m}^{2}$ ). Smoking status (no/yes) and alcohol consumption during pregnancy (no/<10 g/wk $/ \geq 10 \mathrm{~g} / \mathrm{wk}$ ) were determined from the questionnaire assessed during pregnancy. Parents declared their highest diploma obtained, and parental education was defined as the average number of years of education of both mother and father. Information about household income was asked three times: during pregnancy, at 1 and $2 y$ of age. Initially ordered in eight classes ( $1:<450 € /$ month, 2 : $450-800,3: 800-1,500,4: 1,500-2,300,5: 2,300-3,000,6: 3,000-3,800$, $7: 3,800-4,500,8:>4,500)$, we calculated the mean of the three class numbers in order to compute a single continuous variable that covered the period between inclusion and $2 \mathrm{y}$ of age. We obtained the number of siblings by interview, and we determined whether the child was the firstborn (no/yes). From obstetric and pediatric records, we obtained data on offspring's sex, gestational age at delivery, and congenital anomalies. In mailed questionnaires at 4 and 8 mo and at 1 , 2 , and $3 y$ of age, parents reported reasons for child hospitalizations or medical consultations. In the 2-y questionnaire, mothers reported the main caregiver of the child during daytime (mother or family/ nursery or babysitter). An index of the weekly frequency of maternal activities with the child was calculated by averaging the frequencies of storytelling, singing, and playing (7 times/week/3-5 times/week/1-2 times/week/<1 time/week/never). In the 3-y questionnaire, the mothers reported whether the child attended pre-elementary school. The duration of exclusive breastfeeding was calculated using child food 


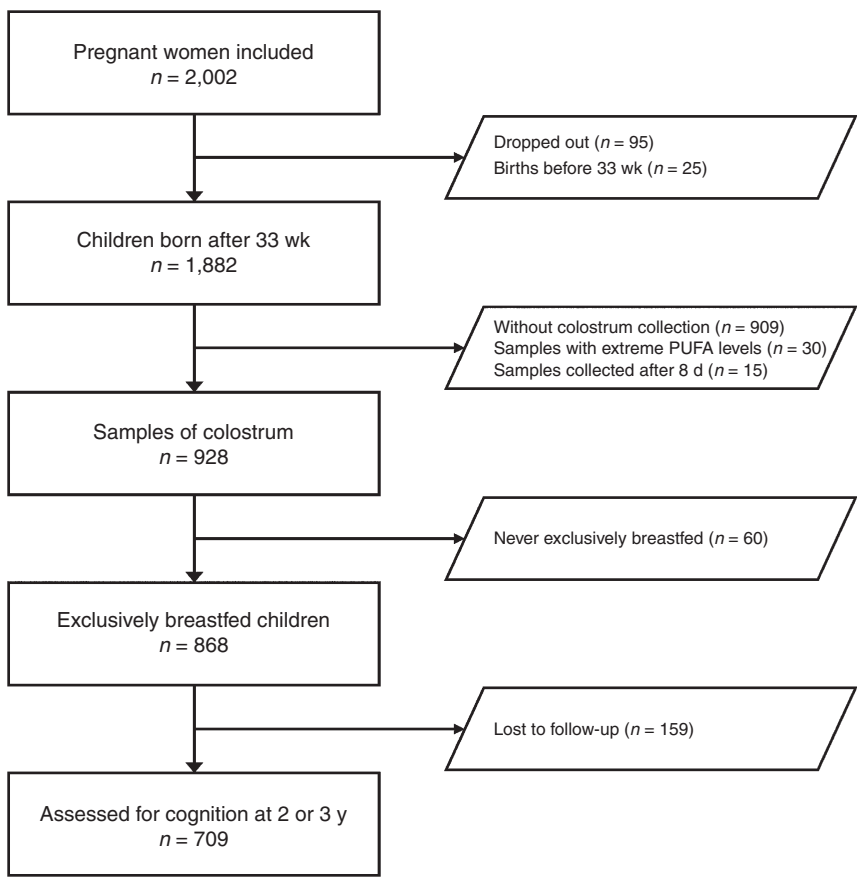

Figure 1. Flowchart of the children with at least one assessment of cognition at 2 or $3 y$ of age in the EDEN mother-child cohort study.

records assessed at 4 and 8 mo after birth, as described in our previous article (3).

\section{Participants}

From the 2002 women included in the cohort, 1,907 babies were born. Children born very preterm (gestational age $<33 \mathrm{wk}, n=25$ ) were excluded from the analysis. Samples of colostrum were available for 980 breastfeeding mothers. Samples collected more than $1 \mathrm{wk}$ after delivery were excluded $(n=15)$, as well as those in which PUFA levels were out of a range comprised between -4 and +4 SD from the mean $(n=30)$. Finally, a total of 709 children exposed to colostrum and who were followed and assessed for at least one cognitive assessment at 2 and $3 \mathrm{y}$ of age were included in the analysis. The Figure 1 shows the flow diagram of the participants.

\section{Statistical Analysis}

Using Student's $t$-test and $\chi^{2}$ test, we compared breastfeeding mothers who gave colostrum sample with those who did not. We reported characteristic of the mother-child pairs with colostrum data with mean \pm SD or percentage $(n)$. We also compared using Student's $t$-test and $\chi^{2}$ test, the characteristics of mother-child pairs with colostrum data, that were lost to follow-up at 2 and $3 \mathrm{y}$ with those that were included in the present analysis (with child cognitive assessment). PUFA levels of populations included and lost to follow-up were described with mean \pm SD and interquartile range and compared with Student's $t$-test. Cognitive assessment scores were described with mean $\pm \mathrm{SD}$ and range.

As a first step, we performed multiple linear regressions to evaluate the relationships of PUFA levels and PUFA ratios (as continuous variables) in colostrum with child cognitive scores. For significant associations, we tested the departure from linearity of the relation by adding the squared term of the PUFA levels in the models. Then, we compared cognitive scores of never breastfed children with those of children breastfed separated in two groups of LA levels in colostrum, according to the median value (9.71\%). Finally, and to evaluate whether associations differed according to breastfeeding duration, we tested the interactions of PUFA levels with breastfeeding duration by adding into the models an interaction term between the PUFA levels and the duration of exclusive breastfeeding. Frequency plots were used to check the distribution of residuals of the regression models.
All models were adjusted for the lapse of time between the delivery and the collection of colostrum, since fatty acid content of colostrum varies over time. We adjusted for exclusive breastfeeding duration, as a proxy of the duration of exposure to breast milk. Models were also adjusted for covariates that have been associated in the literature either to child cognition, to breastfeeding duration, or to breast milk fatty acid content. This concerned the mother (recruitment centre, age at conception, prepregnancy BMI, smoking status, and alcohol consumption during pregnancy), the child (sex, gestational age, age at assessment), and their social environment (sibling, parental education, household income, maternal activities with child, main daytime caregiver). Models explaining cognitive scores at $3 \mathrm{y}$ were additionally adjusted for pre-elementary schooling. Statistical analyses were conducted using SAS 9.3 (SAS Institute, Cary, NC).

\section{ACKNOWLEDGMENTS}

We are grateful to the participating families, the midwife research assistants (Lorraine Douhaud, Sophie Bedel, Brigitte Lortholary, Sophie Gabriel, Muriel Rogeon, and Monique Malinbaum) for data collection, and the data entry operators (Patricia Lavoine, Josiane Sahuquillo and Ginette Debotte). We thank Sophie Kern for providing the French version of the MacArthur Communicative Development Inventory. The EDEN mother-child cohort study group: Isabella Annesi-Maesano, Jonathan Y. Bernard, Jérémie Botton, Marie-Aline Charles, Patricia Dargent-Molina, Blandine de Lauzon-Guillain, Pierre Ducimetière, Maria De Agostini, Bernard Foliguet, Anne Forhan, Xavier Fritel, Alice Germa, Valérie Goua, Régis Hankard, Barbara Heude, Monique Kaminski, Béatrice Larroque, Nathalie Lelong, Johanna Lepeule, Guillaume Magnin, Laetitia Marchand, Cathy Nabet, Rémy Slama, Marie-Josèphe Saurel-Cubizolles, Michel Schweitzer, Olivier Thiebaugeorges.

\section{AUTHOR CONTRIBUTIONS}

M.D., M.A.C., and B.H. designed and conducted this research. J.Y.B. performed the statistical analysis and wrote the paper. M.A. and C.G. performed the analysis of colostrum samples. A.F. was responsible for data management of the EDEN study. All coauthors contributed to the interpretation of the results. All coauthors critically reviewed the manuscript and provided final approval of the version to be published.

\section{STATEMENT OF FINANCIAL SUPPORT}

For the EDEN mother-child cohort study: Fondation pour la Recherche Médicale (FRM), French Ministry of Research IFR and Cohort Program, INSERM Nutrition Research Program, French Ministry of Health Perinatality Program, French Agency for Environment Security (AFFSET), French National Institute for Population Health Surveillance (INVS), Paris-Sud University, French National Institute for Health Education (INPES), Nestlé, Mutuelle Générale de l'Education Nationale (MGEN), French Speaking Association for the Study of Diabetes and Metabolism (Alfediam), National Agency for Research (ANR nonthematic program), Groupes Lipides Nutrition (GNL), and National Institute for Research in Public Health (IRESP TGIR Cohorte Santé 2008 Program). Biological analyses of colostrum samples were funded by the PremUp foundation (foundation for scientific cooperation in connection with pregnancy and prematurity). Study sponsors were not involved in the study design, data collection, or data analyses.

Disclosure: All authors have no conflicts of interest to declare.

\section{REFERENCES}

1. Anderson JW, Johnstone BM, Remley DT. Breast-feeding and cognitive development: a meta-analysis. Am J Clin Nutr 1999;70:525-35.

2. Kramer MS, Aboud F, Mironova E, et al.; Promotion of Breastfeeding Intervention Trial (PROBIT) Study Group. Breastfeeding and child cognitive development: new evidence from a large randomized trial. Arch Gen Psychiatry 2008;65:578-84.

3. Bernard JY, De Agostini M, Forhan A, et al.; EDEN Mother-Child Cohort Study Group. Breastfeeding duration and cognitive development at 2 and 3 years of age in the EDEN mother-child cohort. J Pediatr 2013;163:36-42. e1.

4. Belfort MB, Rifas-Shiman SL, Kleinman KP, et al. Infant feeding and childhood cognition at ages 3 and 7 years: Effects of breastfeeding duration and exclusivity. JAMA Pediatr 2013;167:836-44. 
5. Leventakou V, Roumeliotaki T, Koutra K, et al. Breastfeeding duration and cognitive, language and motor development at 18 months of age: Rhea mother-child cohort in Crete, Greece. J Epidemiol Community Health 2015;69:232-9.

6. Jacobson SW, Chiodo LM, Jacobson JL. Breastfeeding effects on intelligence quotient in 4- and 11-year-old children. Pediatrics 1999;103:e71.

7. Der G, Batty GD, Deary IJ. Effect of breast feeding on intelligence in children: prospective study, sibling pairs analysis, and meta-analysis. BMJ 2006;333:945

8. Koletzko B, Lien E, Agostoni C, et al.; World Association of Perinatal Medicine Dietary Guidelines Working Group. The roles of long-chain polyunsaturated fatty acids in pregnancy, lactation and infancy: review of current knowledge and consensus recommendations. J Perinat Med 2008;36:5-14.

9. Simmer K, Patole SK, Rao SC. Long-chain polyunsaturated fatty acid supplementation in infants born at term. Cochrane Database Syst Rev 2011:CD000376.

10. Schulzke SM, Patole SK, Simmer K. Long-chain polyunsaturated fatty acid supplementation in preterm infants. Cochrane Database Syst Rev 2011:CD000375.

11. Udell T, Gibson RA, Makrides M; PUFA Study Group. The effect of alpha-linolenic acid and linoleic acid on the growth and development of formula-fed infants: a systematic review and meta-analysis of randomized controlled trials. Lipids 2005;40:1-11.

12. Guxens M, Mendez MA, Moltó-Puigmartí C, et al. Breastfeeding, longchain polyunsaturated fatty acids in colostrum, and infant mental development. Pediatrics 2011;128:e880-9.

13. Julvez J, Guxens M, Carsin AE, et al. A cohort study on full breastfeeding and child neuropsychological development: the role of maternal social, psychological, and nutritional factors. Dev Med Child Neurol 2014;56:148-56.

14. Sabel KG, Strandvik B, Petzold M, Lundqvist-Persson C. Motor, mental and behavioral developments in infancy are associated with fatty acid pattern in breast milk and plasma of premature infants. Prostaglandins Leukot Essent Fatty Acids 2012;86:183-8.

15. Gustafsson PA, Duchén K, Birberg U, Karlsson T. Breastfeeding, very long polyunsaturated fatty acids (PUFA) and IQ at $6 \frac{1}{2} 2$ years of age. Acta Paediatr 2004;93:1280-7.

16. Keim SA, Daniels JL, Siega-Riz AM, Herring AH, Dole N, Scheidt PC. Breastfeeding and long-chain polyunsaturated fatty acid intake in the first 4 post-natal months and infant cognitive development: an observational study. Matern Child Nutr 2012;8:471-82.

17. Dunstan JA, Mitoulas LR, Dixon G, et al. The effects of fish oil supplementation in pregnancy on breast milk fatty acid composition over the course of lactation: a randomized controlled trial. Pediatr Res 2007;62:689-94.

18. Antonakou A, Skenderi KP, Chiou A, Anastasiou CA, Bakoula C, Matalas AL. Breast milk fat concentration and fatty acid pattern during the first six months in exclusively breastfeeding Greek women. Eur J Nutr 2013;52:963-73.

19. Lattka E, Rzehak P, Szabó É, et al. Genetic variants in the FADS gene cluster are associated with arachidonic acid concentrations of human breast milk at 1.5 and 6 mo postpartum and influence the course of milk dodecanoic, tetracosenoic, and trans-9-octadecenoic acid concentrations over the duration of lactation. Am J Clin Nutr 2011;93:382-91.

20. Morales E, Bustamante M, Gonzalez JR, et al. Genetic variants of the FADS gene cluster and ELOVL gene family, colostrums LC-PUFA levels, breastfeeding, and child cognition. PLoS One 2011;6:e17181.
21. Bernard JY, De Agostini M, Forhan A, de Lauzon-Guillain B, Charles MA, Heude B; EDEN Mother-Child Cohort Study Group. The dietary n6:n3 fatty acid ratio during pregnancy is inversely associated with child neurodevelopment in the EDEN mother-child cohort. J Nutr 2013;143:1481-8.

22. Marchman VA, Fernald A. Speed of word recognition and vocabulary knowledge in infancy predict cognitive and language outcomes in later childhood. Dev Sci 2008;11:F9-16.

23. Flamant C, Branger B, Nguyen The Tich S, et al. Parent-completed developmental screening in premature children: a valid tool for follow-up programs. PLoS One 2011;6:e20004

24. Rothman KJ. No adjustments are needed for multiple comparisons. Epidemiology 1990;1:43-6.

25. Lattka E, Illig T, Koletzko B, Heinrich J. Genetic variants of the FADS1 FADS2 gene cluster as related to essential fatty acid metabolism. Curr Opin Lipidol 2010;21:64-9.

26. Simopoulos AP. Evolutionary aspects of diet: the omega-6/omega-3 ratio and the brain. Mol Neurobiol 2011;44:203-15.

27. Novak EM, Dyer RA, Innis SM. High dietary omega-6 fatty acids contribute to reduced docosahexaenoic acid in the developing brain and inhibit secondary neurite growth. Brain Res 2008;1237:136-45.

28. Kitson AP, Stark KD, Duncan RE. Enzymes in brain phospholipid docosahexaenoic acid accretion: a PL-ethora of potential PL-ayers. Prostaglandins Leukot Essent Fatty Acids 2012;87:1-10.

29. Calder PC. Dietary modification of inflammation with lipids. Proc Nutr Soc 2002;61:345-58.

30. Patterson E, Wall R, Fitzgerald GF, Ross RP, Stanton C. Health implications of high dietary omega- 6 polyunsaturated Fatty acids. J Nutr Metab 2012;2012:539426.

31. Garcia C, Millet V, Coste TC, et al. French mothers' milk deficient in DHA contains phospholipid species of potential interest for infant development. J Pediatr Gastroenterol Nutr 2011;53:206-12.

32. Lagarde M, Bernoud N, Brossard N, et al. Lysophosphatidylcholine as a preferred carrier form of docosahexaenoic acid to the brain. J Mol Neurosci 2001;16:201-4; discussion 215-21.

33. Drouillet P, Forhan A, De Lauzon-Guillain B, et al. Maternal fatty acid intake and fetal growth: evidence for an association in overweight women. The 'EDEN mother-child' cohort (study of pre- and early postnatal determinants of the child's development and health). Br J Nutr 2009; 101:583-91.

34. Masood A, Stark KD, Salem N Jr. A simplified and efficient method for the analysis of fatty acid methyl esters suitable for large clinical studies. J Lipid Res 2005;46:2299-305.

35. Josse D. Revised Brunet-Lezine Test: Infancy Psychomotor Development Scale. (Brunet-Lézine Révisé: Echelle de Développement Psychomoteur de la Première Enfance). Paris, France: Etablissement d'Applications Psychotechniques, 1997:1-308.

36. Fenson L, Dale PS, Reznick JS, et al. The MacArthur Communicative Development Inventories: User's Guide and Technical Manual. San Diego, CA: Singular Publishing Group, 1993:1-114.

37. Kern S. Le compte-rendu parental au service de lévaluation de la production lexicale des enfants français entre 16 et 30 mois langage en emergence. Glossa 2003;85:48-62.

38. Squires J, Potter L, Bricker D. The ASQ user's guide for the Ages and Stages Questionnaires: A Parent-Completed Child-Monitoring System. 2nd edition. Baltimore, MD: Paul H. Brookes Publishing, 1999:1-157. 